اثرات حفاظتى عصاره ميوه كياه تمثك (Rubus fruticosus L.) بر تغيير ات هورمونهاى تَونادوترويينى، تستوسترون و اسيرماتوزنز در موشهاى صحر ايى نر ديابتيك القاشده با استريتوزوتوسين

نوشين امينى'، عبدالحسين شيروى'، ناصر ميرازى ب، ويدا حجتى؛، رقيه عباسعلى بوركبيرره。

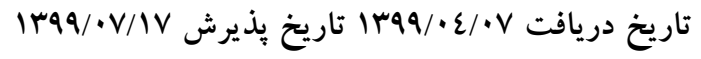

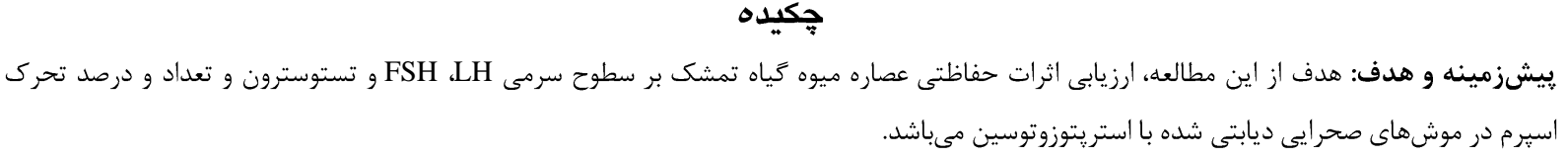

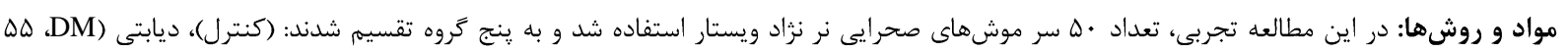

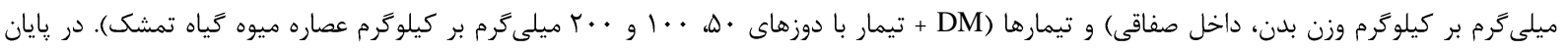

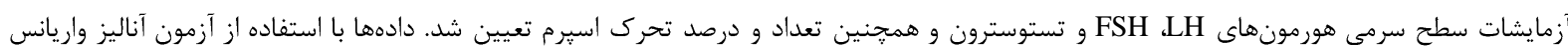
يكسرفه مورد تجزيهوتحليل قرار كرفتند.

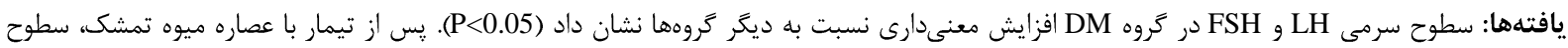

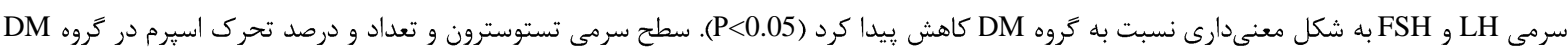

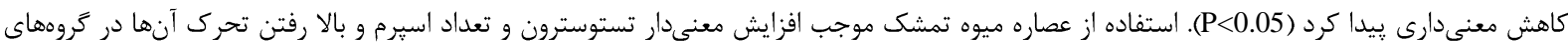
نيمار نسبت به كروه DM شد (P<0.05). نتيجه كيرى: عصاره ميوه تمشك با افزايش ترشح هورمون تستوسترون و بهبود اسيرماتورنز در موشهاى صحر ايى مبتلا به ديابت با STZ منجر به بجببود عملكرد محور هييوفيز-كناد مىشود. كليدوازهها: عصاره تمشك، اسير ماتوزنز، ديابت، موش صحر فيى فيى

مجله مطالعات علوم يزشكى، دوره سى و يكم، شماره نهم، ص 70V-•70، آذر IT99

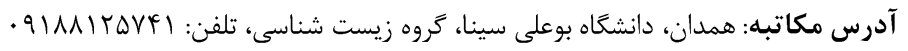
Email: mirazi205@gmail.com

آنها مىتوان به كاهش سطح تستوسترون، تحليل غدد ضميمه

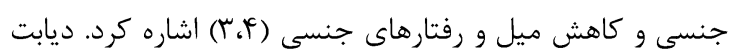

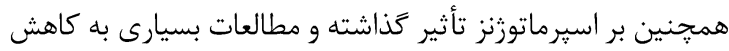

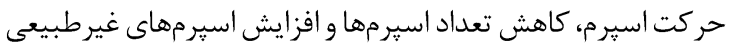

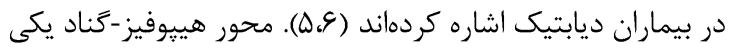

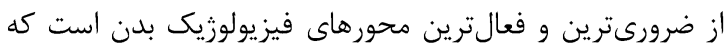

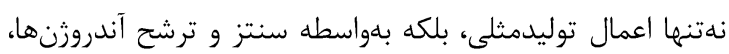

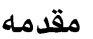
بيمارى قند يا ديابت مليتوس (DM) يك اختلال متابوليك

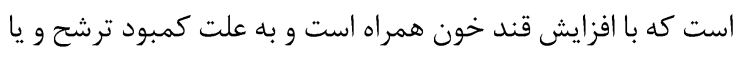

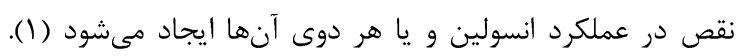
ديابت بر عملكرد و ساختارهاى مختلف بدن ازجمله خشم، كليه و عروق اثر مى كذارد (r). يكى از ساختارهايى كه تحت تأثير آثار سوء

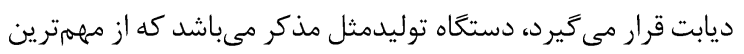

\footnotetext{
أخروه زيست شناسى، واحد دامغان، دانشخاه آزاد اسلامى، دامغان، ايران

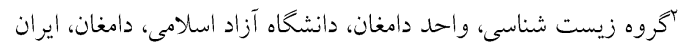

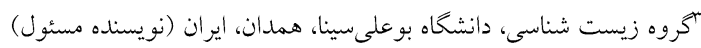

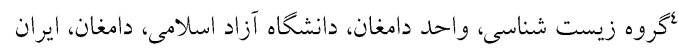

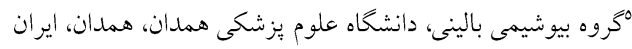


جهت تهيه عصاره، در ابتدا ميوه تمشك از باغات شمال ايران تهيه و توسط مركز تحقيقات كشاورزى مورد شناسايى قرار گرفت. سيس ميوه گياه در شرايط مناسب در سايه خشك، نتخهدارى و

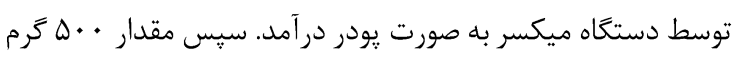

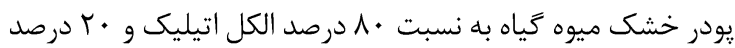

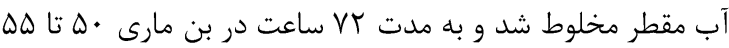
درجه سانتى گراد نغهدارى شد تا عصاره هيدروالكلى كياه تهيه مديه

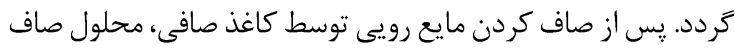

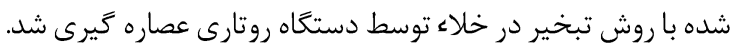

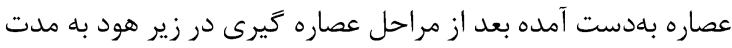

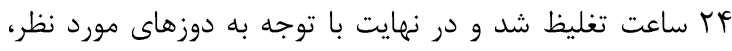

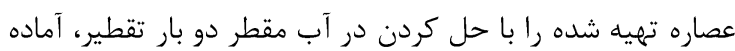

تزريق شد (1) (1) (1).

داروى مورد استفاده براى القاء ديابت، از داروى استر يتوزوتوسين

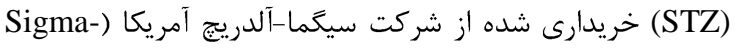
(Aldrich, USA ميلى

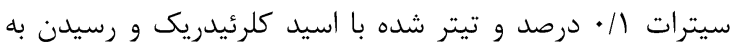
PH=F/D به صورت تك دوز و داخل صفاقى ديابتى شدند (IV) بعد از كذشت Vr ساعت از تزريق STZ، غلظت كلوكز خون با هو خونغيرى از سياهرگ دمى و با استفاده از دستگاه كلوكومتر

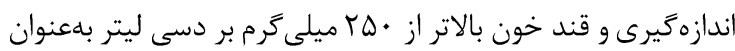

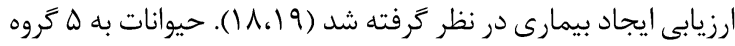

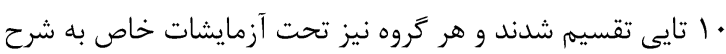
زير قرار گرفتند: گروه كنترل (هيجگَّنه دارويى دريافت نكردند)

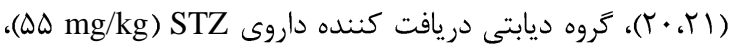

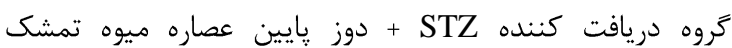
(D.mg/kg)

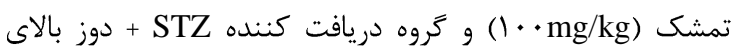

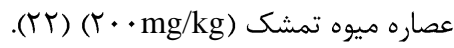
تزريق عصاره در همه كروهها به صورت درون صفاقى روزى يك ميك

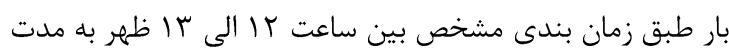

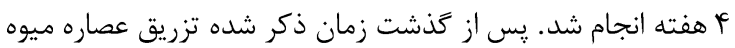

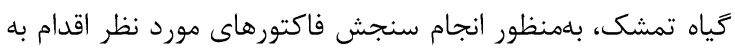

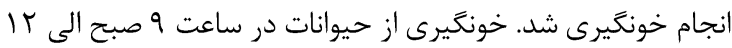
به عمل آمد. روش خونغيرى از قلب باز به صورت مستقيم انجام

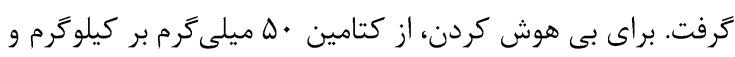
زايلازين • ا ميلى

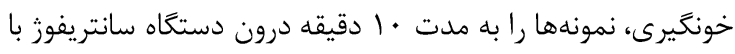
دور . .ب قرار داده و سرم خون تهيه و براى سنجش فاكتورها بكار
بسيارى از جنبههاى فيزيولوزيكى فرد ازجمله تمايز جنسى، بروز صفات ثانويه جنسى و رفتار جنسى را كنترل مى كند (^)، (V). عملكرد دستغاه تناسلى بشدت تحت تأثير هورمونهاى مترشحه از محور

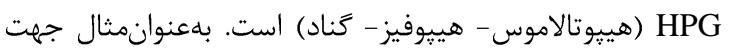
رشد و تقسيم سلولهاى جنسى، تستوسترون از سلولهاى لايديگ ترشح مىشود كه ترشح آن رابطه مستقيمى با ترشئي

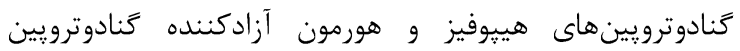

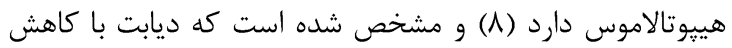

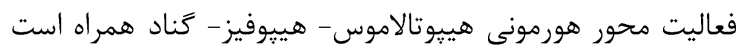

كياهان دارويى سالهاى زيادى است كه در سراسر جهان براى

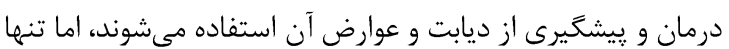

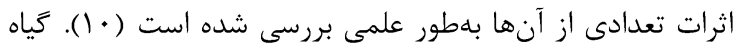
- Rubus fruticosus L.

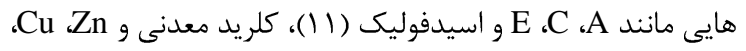

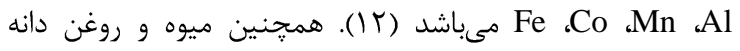
Rubus fruticosus L.

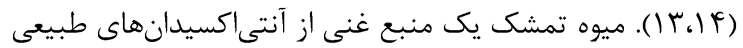

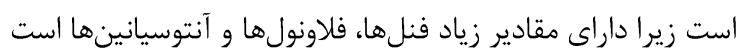
و از مهمترين اثرات تمشك سياه، خاصيت ضدميكروبى، ريك آنتى اكسيدانى، ضدالتهابى و ضدسرطانى است (بر (1). با توجه به اينكه در حال حاضر مطالعات كافى در مورد اثرات كاهشى ميوه تمشك بر إنى

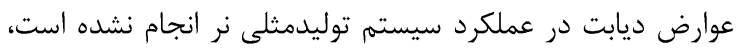

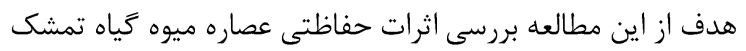

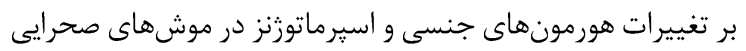

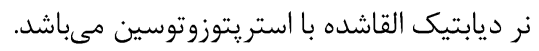

\section{مواد و روشها}

در اين يزوهش تجربى •له سر موش صحرايى نر نزاد ويستار با

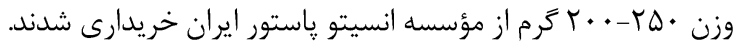
اين موشها در قفسهاى ويزهاى نغاهدارى شده و دماى اتاق

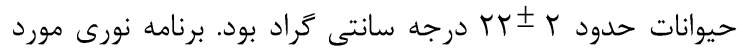
استفاده Y| ساعت روشنايى و T| ساعت تاريكى با شروع روشنايى

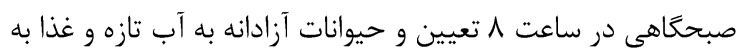
صورت نامحدود دسترسى داشتند. غذاى موشها از كارخانه خوراى دام يارس تهيه شد. در برنامه مطالعاتى، در ابتدا وزن گيرى انجام

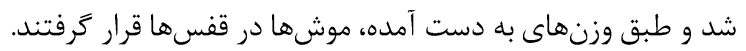
با اين عمل ميانگين وزن هر قفس در يك رنج قرار گرفت و عامل وزن حذف شد. 
غلظت شركت پادتن گَتر ايثار (PGI) صورت گرفت. جهت شمارش

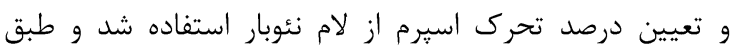

فرمولهاى ارائه شده محاسبه گرديد.
كرفته شد. نمونهاى جمعآورى شده جهت سنجش هورمونى به

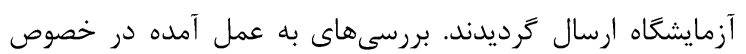

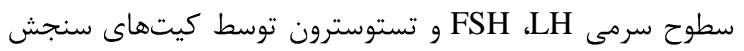

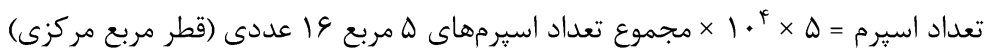

مجموع تعداد اسيرمهاى متحرى • ا ميدان مربع مركزى - = 1 × درصد تحرك اسيرم

مجموع تعداد كل اسيرمهاى • ا ميدان مربع مركزى

كاهش معنادارى نسبت به گروه كنترل شد (P<0.001) در حاليكه

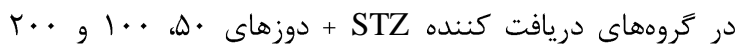
ميلى

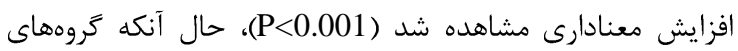

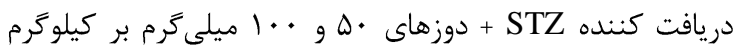
عصاره ميوه تمشك همجنان كاهش معنادارى نسبت به گروه كنترل نشان دادند (P<0.001). از طرفى در بررسى تعداد و درصد تحرى

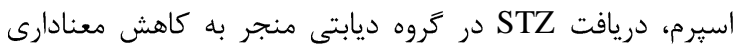

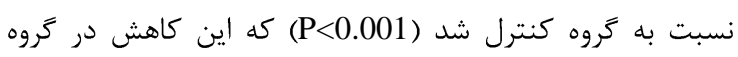
دريافت كنندهى STZ + دوزه • له ميلى كرم بر كيلو گرم عصاره ميوه

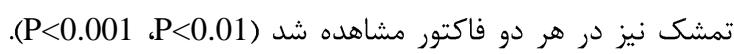

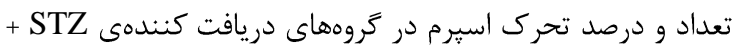

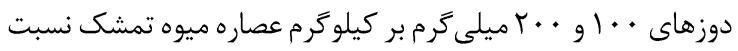

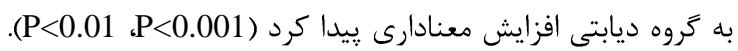

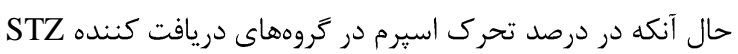

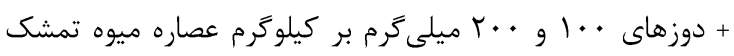
افزايش معنادارى نسبت به كروه كنترل نيز مشاهده شد (P>0.05)

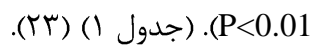

تمامى مراحل آزمايشات مورد تأييد كميته اخلاق دانشعاه علوم يزشكى همدان با كد IR.UMSHA.REC.1399.414 مى باشد.

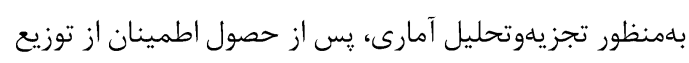

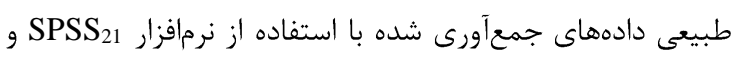

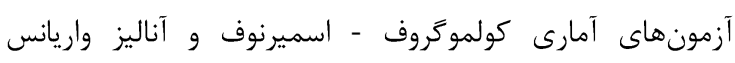
يكسطرفه تجزيهوتحليل شد. سيس از آزمون تعقيبى Tukey جهت بررسى اختلافات بين گروهها استفاده كرديد.

\section{نافتهها}

با توجه به نتايج به دست آمده، سطوح سرمى LSH و FSH در

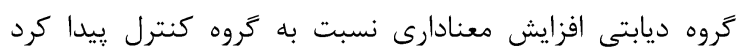

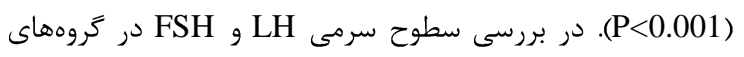

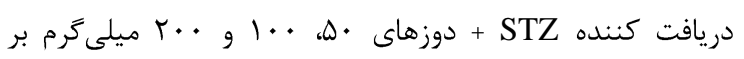

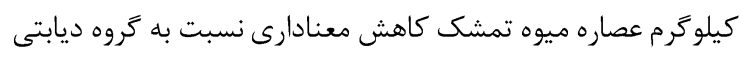

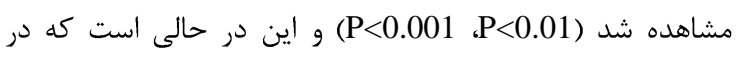

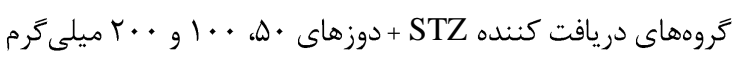
بر كيلوگرم عصاره ميوه تمشك نسبت به گروه كنترل افزايش

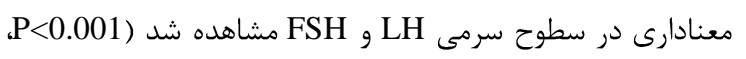
P<0.01

$$
\text { جدول (1): مقايسه ميانگين و خطاى استاندارد ميانگين فاكتورهاى LH ، FSH، تستوسترون، تعداد و درصد تحرك اسيرم در كروههاى }
$$

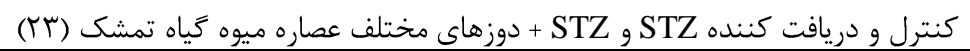

\begin{tabular}{|c|c|c|c|c|c|}
\hline تحرى اسيرم & تعداد اسبرم بر & 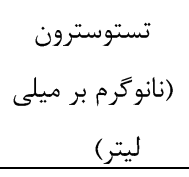 & $\begin{array}{c}\text { FSH } \\
\text { المللى بر ميلى واحد بين ليتر) } \\
\end{array}$ & $\begin{array}{c}\text { LH } \\
\text { المللى بر ميلى واحد بين } 1 \text { اليتر) }\end{array}$ & كروها فاكتور \\
\hline$r / \Delta q \pm V T / \cdot \Delta$ & $9 \cdot 199 \pm 1 \cdots v$ & $. / \cdot T Y \pm F / \Lambda G$ & $\cdot \cdot \cdot \Delta \pm 1 / \Delta T$ & $\cdot 1 \cdot 1 \cdot \pm 1 / \wedge \mathrm{F}$ & كنترل \\
\hline $\begin{array}{c}1 / \Lambda 9 \pm T \cdot / 9 \varphi \\
* * *\end{array}$ & $\begin{array}{c}r q / q) \pm \omega \cdot V \\
* * *\end{array}$ & $\begin{array}{c}\cdot / \cdot \mid r \pm r / 19 \\
* * *\end{array}$ & $\begin{array}{c}\cdot / \cdot r q \pm r / \& V \\
* * *\end{array}$ & $\begin{array}{c}\cdot / \cdots \wedge \pm \Gamma / G \cdot \\
* * *\end{array}$ & ديابتى \\
\hline
\end{tabular}




\begin{tabular}{|c|c|c|c|c|c|}
\hline$r / F \Delta \pm r \mid / \Lambda \Delta$ & $F V / G Y \pm G T V$ & $. / .19 \pm r / \Delta r$ & $\cdot / \cdot 19 \pm 1 / V \wedge$ & $\cdot / \cdot 1 \cdot \pm r / 1 r$ & ديابتى+عصاره تمشك \\
\hline$* * *$ & $* *$ & $* * * \# \# \#$ & *** \#\#\# & *** \#\#\# & • ه ميلى \\
\hline$\varphi / \cdot \Delta \pm \wedge q / 4 \wedge$ & $r I / V q \pm 9 \Delta T$ & $\cdot|\cdot \wedge \pm r / r|$ & $\cdot / \cdot r I \pm I / V \Delta$ & $\cdot \cdot V \pm Y / I V$ & ديابتى+عصاره تمشك \\
\hline$* \# \# \#$ & \#\#\# & $* * * \# \# \#$ & *** \#\#\# & *** \#\#\# & • . ا ميلى \\
\hline $1 / A r \pm q F / \Delta r$ & $\Gamma \wedge / \Delta Q \pm \Lambda \vee G$ & $\cdot 1 \cdot 19 \pm 4 / V q$ & $\cdot 1 \cdot 19 \pm 1 / 9 V$ & $\cdot / \cdot \mid f \pm 1 / 9 f$ & ديابتى+عصاره تمشك \\
\hline **\#\#\# & \#\# & \#\#\# & ** \#\#\# & *** \#\#\# & • . . ميلى Fرم بر كيلو كرم \\
\hline
\end{tabular}

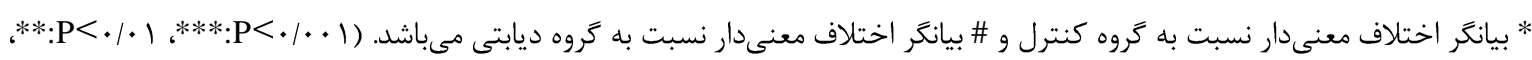

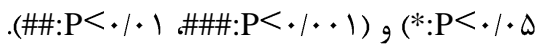

FSH و LH توان احتمال داد كه در اثر ديابت ميزان خونرسانى بافت بيضه كاهش ييدا كرده و با ايجاد شرايط استرس اكسيداتيو، بر ميزان ترشح و رسيدن هورمونهاى كنادوتروبين و در نتيجه عملكرد بيضه

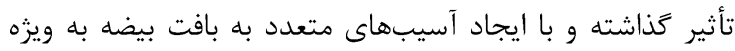

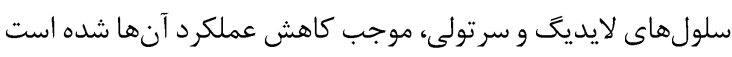
(Y9) كه در نهايت فرايند اسيرماتوزنز دجار اختلال شده و بر تعداد و تحرك اسيرم تأثير خواهد كذاشت.

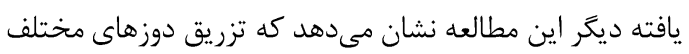

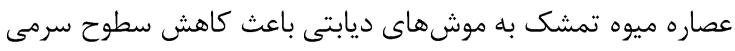
F و افزايش ترشح تستوسترون و همجنين افزايش تعداد و درصد تحرك اسيرم شد كه با نتايج حاصل از برخى مطالعات

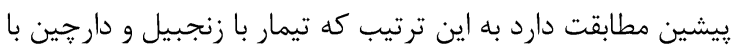
هم به صورت خوراكى، به علت داشتن خواص آنتىاكسيدانى، اثرات قابل ملاحظهاى را بر ميزان قند خون، سطح انسولين و يارامترهاى به

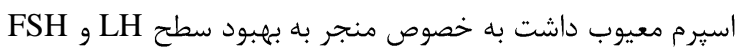

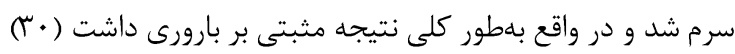

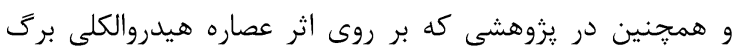

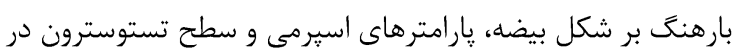
موشهاى نر ديابتى شده با استريتوزوتوسين انجام شد، توانست در بر برهي

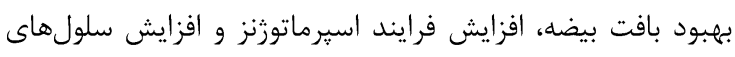

لايدي乏 و تستوسترون مؤثر واقع شود ( آب).

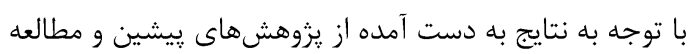

حاضر، مشاهدات نشان دادهاند كه تركيبات فنولى موجود در ميوه تمشك (IF) سبب مهار آسيب سلولهاى لايديگ در حضور

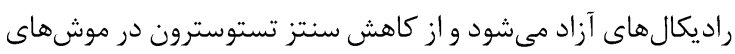

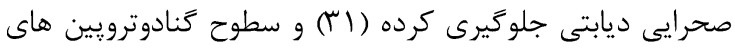

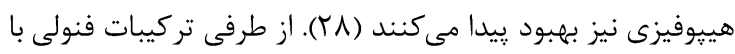

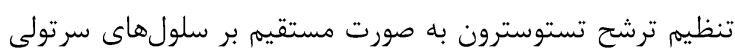

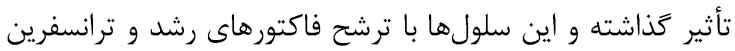

\section{بحث و نتيجهكيرى}

در مطالعه حاضر اثرات حفاظتى عصاره ميوه كياه تمشك دلئى

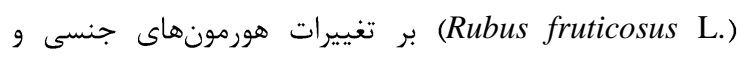
اسيرماتوزنز در موشهاى صحرايى نر ديابتيك القا شده با ندئ

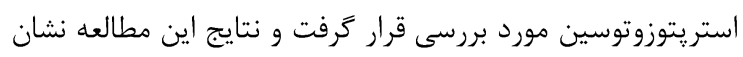

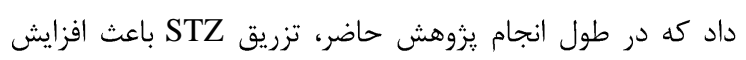
سطوح سرمى LH و FSH و كاهش سطح سرمى تستوسترون و و تعداد و درصد تحرك اسيرم مىشود و اين نتيجه با نتايج مطالعات

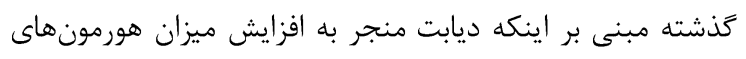

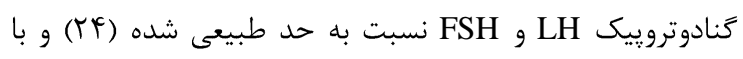
كاهش توليد تستوسترون (Y)، همجنين اسيرماتوزنز (ل) و كاهش

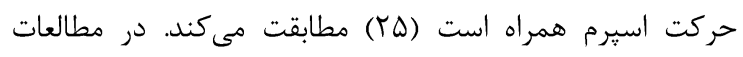

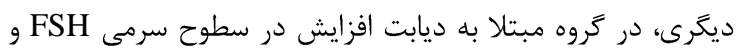
LH به بافت بيضه مىشود و به اين ترتيب سطح سرمى كنادوترويينها

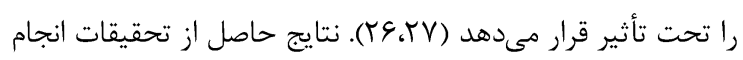

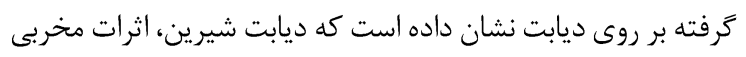

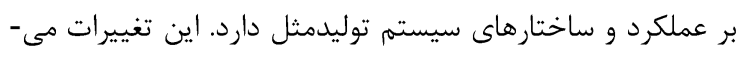
تواند منجر به كاهش سطح تستوسترون، تحليل غدد ضميمه

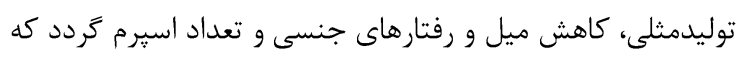

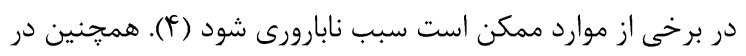

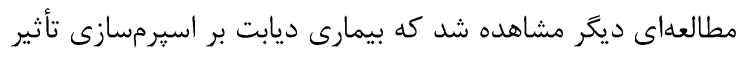
كذاشته و اثر خود را به صورت كاهش در حركت مُ و و تعداد اسيرم و و افزايش ايجاد اسيرمهاى ناهنجار اعمال مىنمايد (· (1).

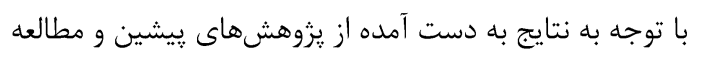

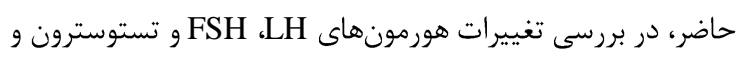

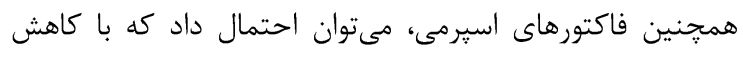

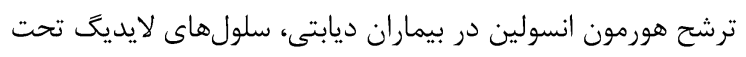
تأثير قرار كرفته و منجر به كاهش ترشح تستوسترون شود (Td) و (T) و با اثر فيدبك منفى براى تنظيم سطح تستوسترون سرم، ميزان ترشح 
اين مطالعه در حيطهى آندوكرينولوزى از بررسى تغييرات

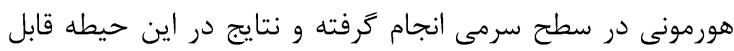

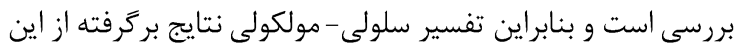

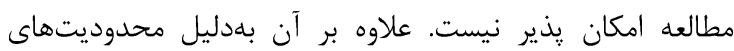

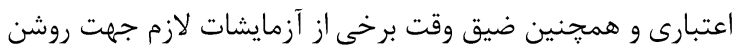

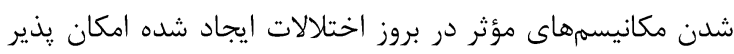
نشد.

$$
\begin{aligned}
& \text { تقدير و تشكر } \\
& \text { اين يزوهش، حاصل پايان نامه مقطع دكتراى تخصصى دانشكاه }
\end{aligned}
$$

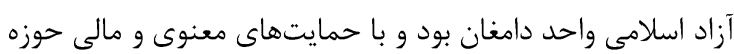

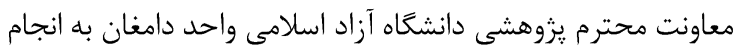

$$
\begin{aligned}
& \text { رسيده است. بدين وسيله از كمك و مساعدت اين عزيزان تقدير و } \\
& \text { تشكر به عمل مى آيد. }
\end{aligned}
$$

\section{References:}

1. Canivell S, Gomis R. Diagnosis and classification of autoimmune diabetes mellitus. Autoimmun Rev 2014; 13: 403-7.

2. Ahmadinasab M, Valipour chahardah charic S, Setorki M. Effect of Crataegus monogyna extract on renal histopathological changes in diabetic rats. Pars Journal of Medical Sciences 2019; 17: 23-31.

3. Bolbol Haghighi N, Molzemi S, Goli Sh, Mohammad Sadeghi H, Aminian M. The Effect of Hydroalcoholic Extract of Ziziphora Clinopodioides Lam on Testicular Damage Caused by Diabetes Mellitus in Male Rats. J Babol Univ Med Sci 2017; 19: 43-9.

4. Soudamani S, Yuvaraj S, Rengarajan S, Sivakumar R,

Malini T, Balasubramanian K. Effects of streptozotocindiabetes and insulin replacement on androgen and estrogen receptor concentrations in the epididymis of Wistar rats. Journal of Endocrinology and Reproduction 2006; 10: 59-61.

5. Sadoughi SD, Edalatmanesh MA, Rahbarian R. The Effect of Curcumin on Pituitary-Gonadal Axis, DNA Oxidative Damage and Antioxidant Enzymes Activity of Testicular Tissue in Male Diabetic Rats.

$$
\begin{aligned}
& \text { در تغذيه و تقسيم سلولهاى جنسى و در نهايت در توليد اسيرم }
\end{aligned}
$$

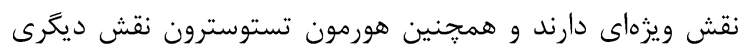

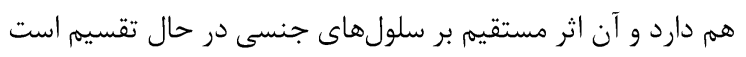

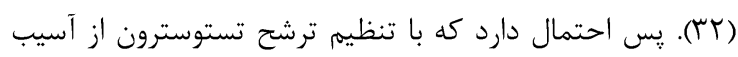

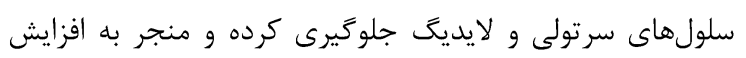

$$
\begin{aligned}
& \text { اسيرمهاى طبيعى از نظر بارورى و تحرك شود. }
\end{aligned}
$$

\section{محدوديتهاي مطالعه}

Journal of Fasa University of Medical Sciences 2018; 7: 511-20.

6. Dadfar F, Mohammadi J, Roshanfekr H. Effect of hydroalcoholic extract of Nectaroscordum tripedale on testicular tissue changes in diabetic male rats. Feyz Sciences 2019; 23: 108-16.

7. Jin J, Yang W. Molecular regulation of hypothalamuspituitary-gonads axis in males. Gene 2014; 551: 15 25.

8. Holdcraft RW, Braun RE. Hormonal regulation of spermatogenesis. Int J Androl 2004; 27: 335-42.

9. Spark RF. Testosterone, diabetes mellitus, and the metabolic syndrome. Curr Urol Rep 2007; 8: $467-$ 71.

10. Taghavi MM, Mahmoudian AR, Pourmasumi S, Jafari Naveh HR, Alavi H. The effect of Angi Pars as an herbal medicine on sperm count and the ratio of testis weight to body weight in diabetic rats. J Mazandaran Univ Med Sci 2011; 24: 68-75.

11. Stoner GD, Chen T, Kresty LA, Aziz RM, Reinemann T, Nines R. Protection against esophageal cancer in rodents with lyophilized berries: Potential mechanisms. Nutr Cancer 2006; 54: 33-46.

12. Ştefănuț MN, Căta A, Pop R, Tănasie C, Boc D, Ienaşcu I, et al. Anti-hyperglycemic effect of 
bilberry, blackberry and mulberry ultrasonic extracts on diabetic rats. Plant Foods Hum. Nutr 2013; 68: 378-84.

13. Yoon J, Cao X, Zhou Q, Ma LQ. Accumulation of Pb, $\mathrm{Cu}$, and $\mathrm{Zn}$ in native plants growing on a contaminated Florida site. Sci Total Environ 2006; 368: 456-64.

14. Zia-Ul-Haq M, Riaz M, De Feo V, Jaafar HZ, Moga M. Rubus Fruticosus L.: Constituents, Biological Activities and Health Related Uses. Molecules 2014; 19: 10998-1029.

15. Shahmohamadi S, Khosravi M, Hajizadeh Moghaddam A. Effect of Salvia officinalis L. extract on malondialdehyde against streptozotocin-induced oxidative stress in rat's brain. Medical sciences 2014; $23: 225-9$.

16. Gomar A, Hosseini A, Mirazi N, Gomar M. Effect of hydroethanolic extract of Rubus fruticosus on neuropathic pain in Wistar diabetic rats. Caspian $\mathbf{J}$ Neurol Sci 2015; 1: 27-34.

17. Pakseresht Z, Norouzi P, Hojati V, Moghaddam Kalalian H. Effect of Palmatine Hydrochloride on Oxidative Stress in Streptozotocin -Induced Diabetic Rats. J Adv Med Biomed Res 2016; 24 : 119-29

18. Shiravi A, Sayyad Zomorrodi M. The study effect of rubus fruticosus extract on cutaneous wound healing in diabetic wistar rat. Iranian Journal of Diabetes and Metabolism 2015; 15: 1-8.

19. Soleimanzadeh A, Malekifard F, Kabirian A. Protective effects of hydro-alcoholic garlic extract on spermatogenic disorders in streptozotocininduced diabetic C57BL/6 mice. Sci J Kurdistan Univ Med Sci 2017; 22: 8-17.

20. Hajinezhad MR, Shapari A, Hajian Shahri S, Sarani F, Salehimoghadam M. Effect of Hydroalcoholic Extract of Berberis Vulgaris Root on Serum Levels of Glucose, Malondehyde and HbA1c in Diabetic Rats. J Neyshabur Univ Med Sci 2015; 3: 21-8.
21. hassanvand V, Yousofvand N, Hatami K. Preventive effect of combining zinc sulphate and garlic flowers extract on diabetes induced by streptozotocin (STZ) in male rats. Journal of Animal Research (Iranian Journal o Biology) 2016; 30: 33-41.

22. Mohammadi Mehdiabadihassani MH, Moradi M, Khoshnam E, Mohammadi SH. The Effects of Hydroalcoholic Extract of Raspberry fruit on Pain and Passive Avoidance Memory Following Transient Global Ischemia/Reperfusion in Wistar Rats. J Med Plants 2017; 16: 137-46.

23. Amini N, Shiravi A, Mirazi N, Hojati V, Abbasalipourkabir R. Protective effects of the raspberry (Rubus fruticosus L.) on pituitary-gonadal axis and testicular histopathology in streptozotosin induced diabetic male rats. Avicenna journal of phytomedicine 2020; Articles in Press.

24. Natah TM, Abdul- Adheem Wtwt M, Al-Saadi HK, Al-Saadi AH, Farhood HF. Study the levels of adiponectin, FSH, LH and Sex hormones in Type 2 diabetes (NIDDM). Journal of Biology, Agriculture and Healthcare 2013; 3: 172-81

25. Ballester J, Munoz MC, Dominguez J, Rigau T, Guinovart JJ, Rodriguez-Gil JE. Insulindependent Diabetes Affects Testicular Function by FSH-and LH Linked Mechanisms. Journal of Andrology 2004; 25: 709-19.

26. Natah TM, Wtwt MA, Al-Saadi HK, Al-Saadi AH, Farhood HF. Study the levels of adiponectin, FSH, LH, and sex hormone in type 2 diabetes (NIIDDM). J Biol Agric Healthcare2013; 3: 172-81.

27. Sönmez MF, Karabulut D, Kilic E, Akalin H, Sakalar C, Gunduz Y, et al. The effects of streptozotocininduced diabetes on ghrelin expression in rat testis: biochemical and immunohistochemical study. Folia Histochem Cytobiol 2015; 53: 26-34.

28. Sepehri H, Rastgar farajzadeh A, ghasemi K. Guyton and Hall textbook of medical Physiology. 13th ed. Tehran: Andishe rafi publications; 2016. 
29. Najar A, Piryae A, Babaei S, bayat M. Effect of pentoxifylline on Sertoli and Leydig cells count of experimentally induced type 1 diabetes in male rats. J Army Univ Med Sci 2013; 11: 188-95.

30. Khaki A, Khaki AA, Hajhosseini L, Sadeghpour Golzar F, Ainehchi N. The anti-oxidant effects of ginger and cinnamon on spermatogenesis dysfunction of diabetes rats. Afr J Tradit Complement Altern Med 2014; 11: 1-8.
31. Nejati V, Khaneshi F. Evaluation of hydro- alcoholic extract of Plantago majo leaf on the changes in testis Morphology, sperm parameters and testosterone level in Streptozotocin- Induced Diabetic Rats. Quarterly of Horizon of Medical Sciences 2014; 20: 49-55.

32. Jasemi M, Saki GH, Rahim F. The Effect of Centella Asiatica Alcoholic Extract on the Serum Levels of Testosterone FSH and LH in Male Wistar Rat. J Sabzevar Univ Med Sci2009; 16:6-11. 


\title{
STUDY OF PROTECTIVE EFFECTS OF RASPBERRY FRUIT EXTRACT (RUBUS FRUTICOSUS L.) ON CHANGES IN GONADOTROPIN HORMONES, TESTOSTERONE AND SPERMATOGENESIS IN MALE DIABETIC RATS INDUCED WITH STZ
}

\author{
Nooshin Amini ${ }^{1}$, Abdolhossein Shiravi ${ }^{2}$, Naser Mirazi*3, Vida Hojati ${ }^{4}$, Roghayeh Abbasalipourkabir $^{5}$
}

Received: 27 June, 2020; Accepted: 07 October, 2020

\begin{abstract}
Background \& Aims: The aim of this study was to evaluate the protective effects of raspberry fruit extract (Rubus fruticosus L.) on LH, FSH, testosterone serum levels, and number and percentage of sperm motility in male diabetic rats induced with streptozotocin.

Materials \& Methods: In this experimental study, 50 Wistar male rats were used and divided into five groups: (control), diabetic (STZ,55mg/kg, i.p), and treatment groups (DM + raspberry fruit extract: 50 , $100,200 \mathrm{mg} / \mathrm{kg} /$ day, 4 weeks). At the end of experiments, the LH, FSH and testosterone serum levels and the number and percentage of sperm motility were examined. The data were statistically analyzed by ANOVA test.

Results: The LH and FSH serum levels increased significantly in DM group compared with other groups $(\mathrm{p}<0.05)$. After treatment with raspberry fruit extract, the LH and FSH serum levels decreased significantly compared with DM group $(\mathrm{p}<0.05)$. The testosterone serum level and the number and percentage of sperm motility decreased significantly in the DM group $(p<0.05)$. The use of raspberry fruit extract significantly increased testosterone serum level and the number and percentage of sperm motility in treatment groups $(\mathrm{p}<0.05)$.

Conclusion: Our results showed that raspberry fruit extract increased testosterone hormone in DM rats, and also improved spermatogenesis and ameliorating pituitary-gonadal axis function.

Keywords: Raspberry extract, Spermatogenesis, Diabetes, Rat

Address: Department of Biology, Faculty of Basic Sciences, Bu- Ali Sina University, Hamedan, Iran Tel: +989188125741

Email: mirazi205@gmail.com
\end{abstract}

SOURCE: STUD MED SCI 2020: 31(9): 657 ISSN: 2717-008X

\footnotetext{
${ }^{I}$ Department of Biology, Damghan Branch, Islamic Azad University, Damghan, Iran

${ }^{2}$ Department of Biology, Damghan Branch, Islamic Azad University, Damghan, Iran

${ }^{3}$ Department of Biology, Faculty of Basic Sciences, Bu- Ali Sina University, Hamedan, Iran (Corresponding

Author)

${ }^{4}$ Department of Biology, Damghan Branch, Islamic Azad University, Damghan, Iran

${ }^{5}$ Department of Clinical Biochemistry, School of Medicine, Hamedan University of Medical Sciences, Hamedan, Iran
} 